\title{
NITRIDATION EFFECTS ON THE OXIDATION MECHANISMS OF AN ODS FeAI INTERMETALLIC ALLOY
}

F. Pedraza*, J.L. Grosseau-Poussard and J.F. Dinhut

LEMMA, Université de La Rochelle. 25, rue Enrico Fermi, 17042 La Rochelle Cedex 1, FRANCE.

* Corresponding author: Phone: +33 (0)546458697, Fax: + 33 (0)546457272, e-mail: fpedraza@univ-lr.fr

\section{Abstract}

An ODS FeAl intermetallic alloy has been nitrided at low-energy high flux implantation diffusion leading to the formation of hexagonal AIN and $\alpha$-Fe segregation. Its high temperature behaviour is subsequently evaluated under isothermal oxidation at $800^{\circ} \mathrm{C}$. Microscopy techniques (SEM, TEM) will show that nitridation hinders aluminium outward diffusion and enhances iron outward diffusion giving rise to a layered structure.

\section{1.- Introduction}

Upon the high temperature oxidation of titanium aluminides, TiN and/or $\mathrm{Ti}_{2} \mathrm{AlN}$ subscales have been observed to develop at the substrate/oxide interface $[\mathbf{1 , 2}]$, which sometimes have been referred to provide an effective barrier for outward Al diffusion [3] or to prevent oxygen dissolution in the alloy [4] thus improving their oxidation resistance. When these alloys are nitrided, the same nitrogen containing phases appear [5] but only detrimental effects have been reported to occur compared to non nitrided specimens owing to a lower amount of $\mathrm{Al}_{2} \mathrm{O}_{3}$ developed at the top surface [6-8].

In the case of iron aluminides without oxygen-active elements, their oxidation behaviour is worse in air than in pure oxygen due to internal nitridation below a defective alumina scale [9]. Pint et al. [10] indicated that on $\mathrm{Fe}_{3} \mathrm{Al}$ this could result by either simultaneous nitridation and oxidation or, once the scale had been formed, by a reduced oxygen partial pressure in contrast to a high nitrogen pressure. The latter mechanism seems to better agree with the findings of $\mathrm{Xu}$ et al. on FeAl [11]. However, the effects of nitridation have only been scarcely studied. Choe [12] employed ion implantation at $150 \mathrm{keV}$ to nitride different $\mathrm{Fe}_{3} \mathrm{Al}$ (with and without $\mathrm{Cr}$, Mo and $\mathrm{B}$ ) resulting in the formation of $\mathrm{AlN}, \mathrm{Fe}_{4} \mathrm{~N}, \mathrm{CrN}$ and even $\alpha$-Fe, which enhanced the 
corrosion resistance to acid media. More recently, the effects of an ion nitriding treatment on the oxidation behaviour of an ODS FeAl alloy have been discussed [13], indicating the formation of AIN and again of $\alpha$-Fe after the nitridation treatment, the latter element diffusing outwardly upon oxidation to form iron oxides. As a result, the nitridation treatment is concluded not to be beneficial. It is therefore intended in this work to provide additional insight on the nitridation of an yttria dispersed FeAl and its subsequent oxidation behaviour at $800^{\circ} \mathrm{C}$. This temperature has been chosen since previous studies on iron aluminides have only focused on temperatures higher than $900^{\circ}$ $\mathrm{C}[\mathbf{1 0 , 1 1}]$

\section{2.- Experimental}

Low energy - high flux nitrogen implantation of $1 \mu \mathrm{m}$ polished FeAl Grade 3 [15 ppm B, $0.1 \mathrm{wt} \% \mathrm{Zr}, 1 \mathrm{wt} \% \mathrm{Y}_{2} \mathrm{O}_{3}$, CEA/CEREM (Grenoble, France)] was carried out at 1.2 $\mathrm{keV}$ and $1 \mathrm{~mA} . \mathrm{cm}^{-2}$ up to a dose of $3.5 \times 10^{19}$ at. $\mathrm{cm}^{-2}$ while controlling the temperature not to exceed $400^{\circ} \mathrm{C}$. Prior to nitridation, $\mathrm{Ar}^{+}$sputtering was carried out on each main coupon face to remove the rigid oxide layer that precludes nitridation [14]. The backing pressure in the chamber upon the nitriding process was better than $10^{-2} \mathrm{~Pa}$. Implantation was carried out on both principal coupon faces for the subsequent oxidation experiments, representing about $85 \%$ of the overall surface.

Oxidation of the nitrided specimens was conducted in a Setaram TG DSC92 thermobalance of $10^{-6} \mathrm{~g}$ of accuracy at $800^{\circ} \mathrm{C}$ for $24 \mathrm{~h}$ under synthetic air. Heating and cooling rates were fixed at $50^{\circ} \mathrm{C} / \mathrm{min}$

Characterisation was undertaken by conventional XRD in a Bruker AXS D-5005, AFM in the contact mode with an Autoprobe CPR (Veeco Instruments),SEM/EDS in a JEOL JSM-5410 LV and TEM/EDS in a JEOL-JEM 2010 at $200 \mathrm{kV}$. For the preparation of the cross sections of the implanted and the oxidised specimens careful mechanical polishing in SiC\# 4000 emery paper was performed down to a thickness of about 50 $\mu \mathrm{m}$. Then, Ar bombardment at $3 \mathrm{keV}$ was carried out in a GATAN PIPS ${ }^{\mathrm{TM}}$ (precision ion polishing system) model 691 at different angles. 


\section{3.- Results}

\section{1.- Nitridation}

The surface of the nitrided specimens appeared to be homogeneous with protrusions at the top surface and remains of porosity. The former seemed to be pinned by yttria particles [15]. The EDS average surface composition was of 55\% $\mathrm{Fe}-25 \% \mathrm{Al}$ and $20 \%$ $\mathrm{N}$ (at\%). However, by inspecting the cross sections a non planar nitridation front is observed to occur [Figure 1(a)] with an outer compound layer and an inner diffusion layer. After chemical etching, the structure of the nitrided layer is better revealed, with outward growing protuberances as well as grains of submicron size constituting the nitrided layer. The alloy itself shows the alignment of the grains composing this alloy fabricated by powder metallurgy and extruded in the $<110>$ direction $[\mathbf{1 3}, \mathbf{1 6}]$.

TEM analysis again showed equiaxed grains of submicron scale throughout the nitrided layer and a diffusion layer more compact than the compound layer. Figure 2 (a) shows the EDS (TEM) analyses across the full nitrided layer. The amount of nitrogen decreases gently from the top surface although a jump is observed at about $0.75 \mu \mathrm{m}$ from the surface, which seems to differentiate the compound layer (top) from the diffusion layer (bottom). Some oxygen impurities are present all across the nitrided layer. The aluminium concentration is almost constant across the nitrided layer but the iron amount increases from the top surface towards the substrate exceeding its original content in the alloy. Closer TEM inspection at this region shows iron segregating at the nitrided layer/substrate interface [Figure 2 (b)]. Selected area diffraction patterns (SADPs) across the different regions reveal the exclusive formation of hexagonal AIN and $\alpha$-Fe together with fragmentation (diffused rings) of the outer FeAl grains of the alloy [15] The conventional XRD confirmed the presence of such three species [13].

\section{2.- Oxidation}

After the $24 \mathrm{~h}$ exposure at $800^{\circ} \mathrm{C}$, the weight gains of the nitrided specimens was fourfold that of the un-nitrided, with parabolic rate constants of about $4.7 \cdot 10^{-8} \mathrm{mg}^{2} \cdot \mathrm{cm}^{-4} \cdot \mathrm{s}^{-1}$ for the latest stage [13], i.e. even 10 times faster than those of nitrided $\alpha$-iron [17].

After cooling, the oxide scales are shown to extensively spall off (Figure 3), depicting at least two subscales, a very convoluted top layer and an inner layer with white needles. 
Although the surface EDS microanalysis and XRD only indicated the presence of iron oxide (hematite), TEM inspection reveal a more complex oxide scale as shown in Figure 4 (a). Owing to the spallation phenomenon, preparation of the electron transparent cross section was a hard task but this figure clearly depicts stratification, which in turn indicates different oxidation mechanisms, as confirmed by the EDS ( $3 \mathrm{~nm}$ spot) microanalyses across the entire scale [Figure 4 (b)]. Indeed, the outermost oxide layer is only constituted of iron and oxygen and of about $0.25 \mu \mathrm{m}$ thick. According to the XRD patterns [13] this phase has been identified as $\alpha-\mathrm{Fe}_{2} \mathrm{O}_{3}$.Underneath, a $0.2 \mu \mathrm{m}$ thick layer exists, which is mostly enriched in aluminium, which may correspond to $\alpha$ $\mathrm{Al}_{2} \mathrm{O}_{3}$. The inner oxide layer is the largest (about $0.5 \mu \mathrm{m}$ thick) with more of $\mathrm{Al}$ than $\mathrm{Fe}$ as plotted Figure 4 (b), indicating the possibility of a $\mathrm{FeAl}_{2} \mathrm{O}_{4}$ spinel phase. It is right at the spinel substrate interface that nitrogen is found to concentrate, accompanied with a drop in the oxygen content. As shown in Figure 4 (c), the selected area diffraction patterns (SADPs) at the top and bottom inner scale confirm the existence of the $\mathrm{FeAl}_{2} \mathrm{O}_{4}$ phase, with contribution of hexagonal AlN at the oxide/substrate interface, whose reflections are summarised in Table 1.

Table 1.- Experimental d-spacings obtained from SADPs at the inner oxide layer / substrate interface after oxidation at $800^{\circ} \mathrm{C}$ of the nitrided ODS FeAl and their correspondence to the planes of the identified compounds.

\begin{tabular}{ccc}
\hline d-spacing, $\AA$ & $\begin{array}{c}\mathbf{F e A l}_{2} \mathbf{O}_{\mathbf{4}} \\
\text { (JCPDS 34-192) }\end{array}$ & $\begin{array}{c}\text { AlN } \\
\text { JCPDS 25-1133 }\end{array}$ \\
\hline 4.65 & 111 & - \\
2.70 & - & 100 \\
2.46 & 311 & 002 \\
2.04 & 400 & - \\
1.86 & 331 & 102 \\
1.39 & - & 103 \\
\hline
\end{tabular}




\section{4.- Discussion}

\section{1.- Nitridation}

Upon the nitridation of aluminium-containing alloys, supersaturation of nitrogen in aluminium or the formation of AlN may occur [18]. However, the thermodynamic stability of the growing phase also plays an important role. In the FeAl alloy, the chemical affinity of $\mathrm{N}$ to $\mathrm{Al}$ is much greater than that to $\mathrm{Fe}[\mathbf{1 9}]$ and as such, only AIN formation is observed under the present experimental conditions. According to Sonnleitner et al. [20] the polycrystalline hexagonal AlN only develops if the nitrogen content is between $15-25$ wt\%, which is possibly non stoichiometric owing to the reconstruction of surface atoms upon implantation [19]. In the present study, only the outer compact layer would have enough nitrogen to form AlN but as its content decreases towards the substrate, the nitride is found diluted in a FeAl / $\alpha$-Fe matrix, which agrees well with the previous investigation reported in [13]. $\alpha$-Fe seems to result as a by-product from the reaction of nitrogen with aluminium during the implantation process. It is believed that AlN formation starts at the surface of the FeAl grains and further penetrates into them thus inducing their fragmentation [15]. This brings about the creation of more grain boundaries through which nitridation is promoted (also incorporating some oxygen) and aluminium is transported towards the surface, as revealed by the constant profile shown in Figure 2 (a). Iron outward diffusion is in turn hindered since the diffusion coefficient of indium (isoelectronic to aluminium) has been shown to be about twice than that of iron in $\mathrm{Fe}_{66} \mathrm{Al}_{34}$ and $\mathrm{Fe}_{50} \mathrm{Al}_{50}$ [21].

After nitridation, the porosity of this sintered material still remains but the protrusions are likely to result from the gas bubble formation [22] which may surpass the yield stress of the parent material thus inducing deformation [23]. Since the intermetallic alloy is strengthened by a dispersion of $\mathrm{Y}_{2} \mathrm{O}_{3}$ particles, those areas lacking of such particles are more prone to deform and thus the material flows in an elongated shape.

\section{2.- Oxidation}

The isothermal oxidation at $800^{\circ} \mathrm{C}$ of the nitrided ODS FeAl has shown to bring about extensive spallation of the oxide scale. This is thought to occur upon cooling of the specimens since no humps in the oxidation curve were recorded during the test [13]. As mentioned above, the surface after nitridation is plastically deformed (protrusions), 
which may bring about high stress gradients within the oxide scale upon cooling bringing about the observed detachment. Convolution of the oxide scale had already been observed by $\mathrm{Xu}$ et al. [11] oxidised at $1100^{\circ} \mathrm{C}$ on the same substrate, in which only alumina scales formed together with AlN at the inner oxide interface.

In this study, the oxidation rate is about ten times faster than that of nitrided iron [17]. Indeed, it has been shown that layered oxide scale is formed after oxidation composed of an outer hematite layer, central alumina and inner Fe-Al spinel scale. The latter besides contains AlN at the interface with the substrate. Such complex structure seems to derive from the following oxidation mechanism. Although outward diffusion of indium (aluminium) is two times faster than that of iron in $\mathrm{Fe}_{66} \mathrm{Al}_{34}$ and $\mathrm{Fe}_{50} \mathrm{Al}_{50}$ [21], there is not enough aluminium available at the top surface to form the oxide since this is trapped as AIN throughout the compact layer. At the diffusion layer, $\alpha$-Fe was found to segregate at the fragmented FeAl matrix together with some AlN. Such iron is readily available for outward diffusion through the important number of short circuit paths that represent the grain boundaries and defaults created upon nitridation. However, once the outer iron scale is developed, the oxygen partial pressure decreases and only aluminium oxide is able to form owing to its higher thermodynamic stability. Although at reduced pressure only the $\alpha-\mathrm{Al}_{2} \mathrm{O}_{3}$ phase develops, the appearance in Figure 3 of the typical needle or plate-like morphology indicates the presence of the $\theta-\mathrm{Al}_{2} \mathrm{O}_{3}$ phase [24]. Both the $\mathrm{Fe}_{2} \mathrm{O}_{3}$ and the $\theta-\mathrm{Al}_{2} \mathrm{O}_{3}$ phases are known to contain an important amount of defects through which oxygen can be transported inwardly [25] resulting in the formation of the spinel phase underneath the alumina scale. The Fe-Al spinel phase has been reported to originate from either the $\mathrm{Fe}_{2} \mathrm{O}_{3}$ and $\mathrm{Al}_{2} \mathrm{O}_{3}$ reaction [26] or from the $\mathrm{FeO}$ and $\mathrm{Al}_{2} \mathrm{O}_{3}$ one [27]. This is confirmed from the EDS microanalysis of Figure 4(b) in which the oxygen amount is constant across the entire oxide scale. At reduced oxygen partial pressures dissolution of AlN also takes place [11] and indeed, no nitrogen is found in any of the oxide layers except at the spinel / substrate interface. This implies that after dissolution of the nitride, nitrogen seems to diffuse inwardly towards the substrate whereas the resulting aluminium tends to be transported outwardly, stabilising the spinel oxide phase. The presence of such spinel phase has also been observed at the same location on non nitrided specimens at temperatures of 850 and $950^{\circ} \mathrm{C}$ [28] and seemed to form prior to the development of the outer alumina scale. In such study it was already 
claimed that the spinel layer would only be partially effective in hindering outward aluminium diffusion when the grains coarsened with increasing temperature . Therefore, a change in the oxidation mechanism of FeAl Grade 3 results from the presence of implanted nitrogen. Overall, its role is that of retarding the establishment of an external alumina scale, but does not seem to impede it. Longer oxidation tests should be carried out to confirm this possibility. It also has to be remarked that no contribution of the yttria dispersed phase has been found and its role does not seem to affect the oxidation behaviour of $\mathrm{FeAl}$ at $800^{\circ} \mathrm{C}$.

\section{5.- Summary and conclusions}

The nitridation by implantation-diffusion of FeAl Grade 3 brings about the formation of an outer AlN compact layer and an inner diffusion layer in which AlN, $\alpha$-Fe segregation and fragmentation of the FeAl grains occur. Deformation of the material also seems to be induced upon implantation. After the isothermal oxidation at $800^{\circ} \mathrm{C}$ of the nitrided ODS FeAl extensive spallation of the oxide takes place as a result of the stress gradient in the deformed nitrided material which is exacerbated upon cooling. The derived oxidation mechanisms seems to be as follows: since aluminium is trapped as AlN, an outer $\mathrm{Fe}_{2} \mathrm{O}_{3}$ scale is first established at the gas/metal interface as a result of iron outward diffusion. Once the outer layer is formed, the oxygen partial pressure is reduced and only $\alpha-\mathrm{Al}_{2} \mathrm{O}_{3}$ can be formed (with some contribution of $\theta-\mathrm{Al}_{2} \mathrm{O}_{3}$ ). Such reduction in the oxygen partial pressure provokes the dissolution of AlN, and then nitrogen is further transported inwardly, whereas cation outward diffusion occurs. As a result, the spinel inner layer is developed. Therefore, the nitridation treatment changes the oxidation mechanisms of the same substrate, in which typically the spinel phase is first established through which outward aluminium diffusion occurs to develop an outer alumina scale.

\section{6.- Acknowledgements}

This work was carried out under the post doctoral stay of F. Pedraza, funded by the Region of Poitou-Charentes (France). Special thanks are directed to Mr. G. Abrasonis and Prof. Rivière (CNRS-UMR-6630, Poitiers, France) for the nitridation experiments. 


\section{7.- References}

1. V.A.C. Haanappel, J.D. Sunderkotter, M.F. Stroosnijder, Intermetallics 7 (1999) 529-541.

2. D.B. Lee, M.H. Kim, C.W. Yang, S.H. Lee, M.H. Yang, Y.J. Kim, Oxid. Met. 56 (2001) 215-229.

3. J.S Wu, L.T. Zhang, F. Wang, K. Jiang, G.H. Qiu, Intermetallics 8 (2000) 19-28.

4. P. Pérez, P. Adeva, Ox. Met. 56 (2001) 271-285.

5. J. Magnan, G.C. Weatherly, M.C. Cheynet, Met. Mat. Trans 30A (1999) 19-29.

6. B. Zhao, J. Wu, J. Sun, F. Wang, Intermetallics 9 (2001) 697-703.

7. J. Sun, J.S. Wu, B. Zhao, F. Wang, Mat. Sci. Eng. A329-331 (2002) 713-171.

8. B. Zhao, J. Wu, J. Sun, B. Tu, F. Wang, Mat. Letters 56 (2002) 533-538.

9. P.F. Tortorelli, K. Natesan, Mat. Sci. Eng. A258 (1998) 115-125.

10. B.A. Pint, J.R. Regina, K. Prüßner, L.D. Chitwood, K.B. Alexander, P.F. Tortorelli, Intermetallics 9 (2001) 735-739.

11. C.H. Xu, W. Gao, Y.D. He, Scripta. Mater. 42 (2000) 975-980.

12. H.C. Choe, Surf. Coat. Technol. 148 (2001) 77-87.

13. C. Dang Ngoc Chan, C. Huvier, J.F: Dinhut, Surf. Coat. Technol. 165 (2003) 119125.

14. Y. Ando, S. Tobe, H. Tahara, T. Yoshikawa, Vacuum 65 (2002) 403-408.

15. F. Pedraza, J.L. Grosseau-Poussard, Thin Solid Films, Nitridation treatment of an ODS FeAl intermetallic alloy, submitted.

16. M.A. Montealegre, J.L. González Carrasco, M.A. Morris-Muñoz, J. Chao, D.G. Morris, Intermetallics 8 (2000) 439-446.

17. R.H. Jutte, B.J. Koi, A.J. Sommers, E-J. Mittemeijer, Oxid. Met. 48 (1997) 87-110.

18. A.M. Serventi, M. Vittori Antisari, Phil. Mag. B76 (4) (1997) 549-557.

19. H.K. Sanghera, J.L. Sullivan, Surf. Interface Anal. 27 (1999) 678-690.

20. R. Sonnleitner, K. Spiradek-Hahn, F. Rossi, Surf. Coatings Technol. 156 (2002) 149-154.

21. H. Mehrer, M. Eggersmann, A. Gude, M. Salamon, B. Sepiol, Mat. Sci. Eng. A239240 (1997) 889-898.

22. M.F. Denanot, J. Delafond, J. Grilhé, Rad. Effects 88 (1986) 145-151.

23. A.P. Matthews, M. Iwaki, Y. Horino, M. Satou, K. Yabe, Nucl. Inst. Meth. Phys. Res. B59/60 (1991) 671-675.

24. M.A. Montealegre, J.L. González-Carrasco, Intermetallics, 11 (2003) 169-175. 
25. F.J. Pérez, F. Pedraza, M.P. Hierro, J. Balmain, G. Bonnet, Oxid. Met. 58 (2002) 563-588.

26. T. Fujimura, S.I. Tanaka, J. Mater. Sci. 34 (1999) 425-429.

27. S.E. Sadique, M.A.H. Mollah, M.M. Ali, M.M. Haque, S. Basri, M.M.H.M. Ahmad, S.M. Sapuan, Oxid. Met. Vol. 54 Nos. 5/6 (2000) 385-400.

28. F. Pedraza, J.L. Grosseau-Poussard, J.F. Dinhut, Intermetallics 13 (2005) 27-33. 

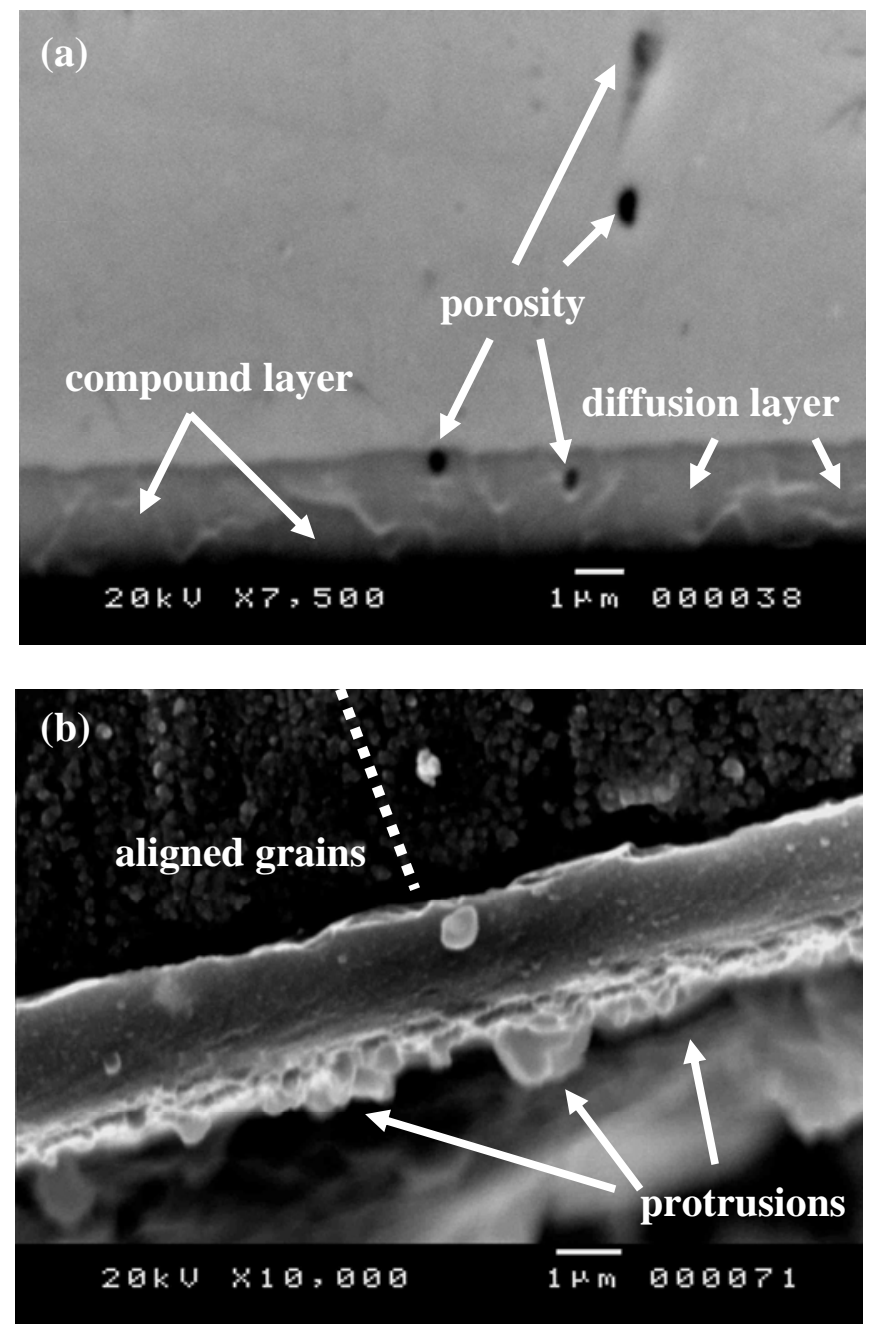

Figure 1.- SEM cross sections of the nitrided specimens (a) unetched showing irregular nitrided front and (b) etched condition revealing the surface protrusions. 

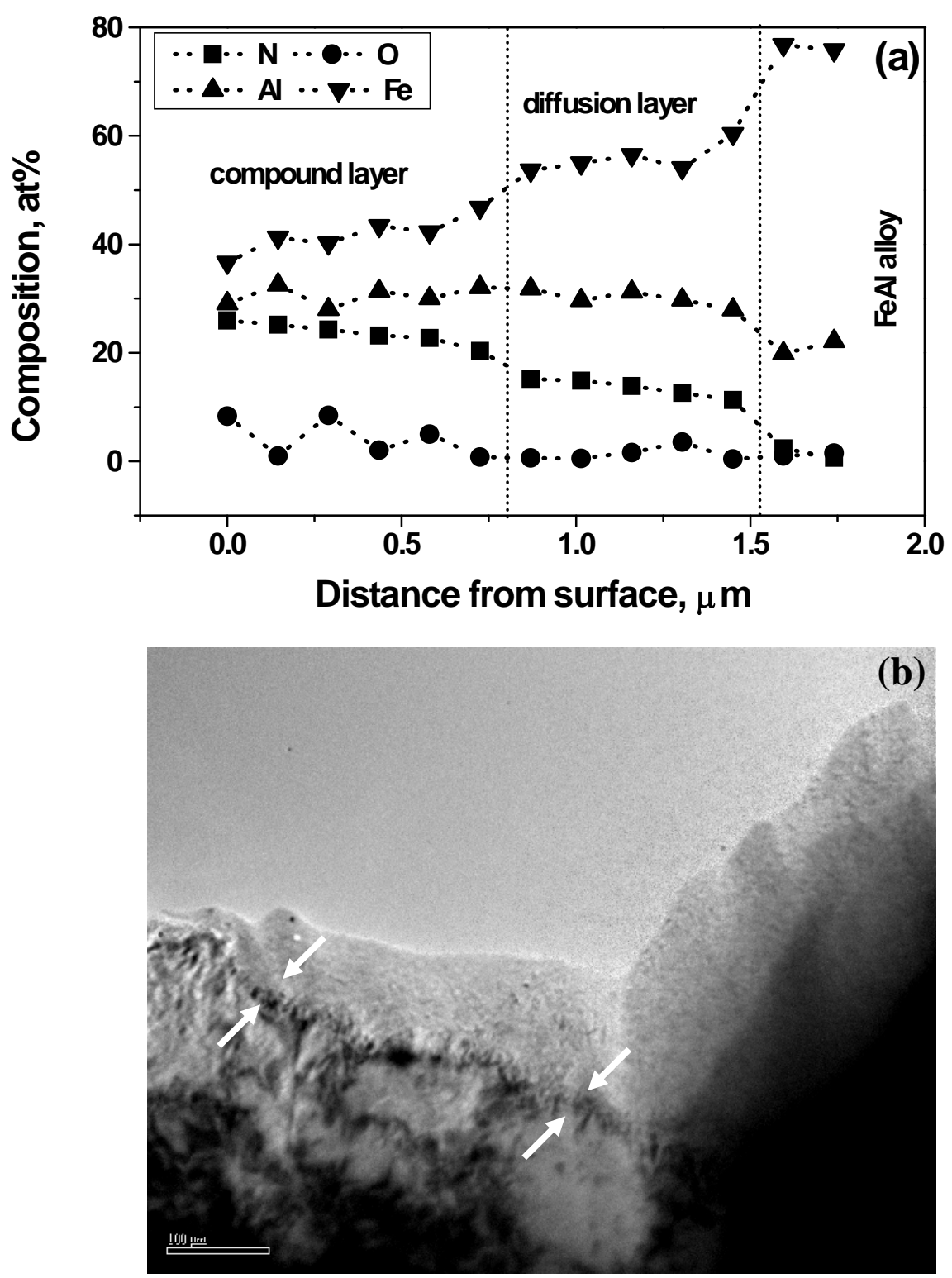

Figure 2.- (a) EDS analysis across the entire nitrided layer and (b) TEM cross section showing the nitrided layer/substrate interface. The band of $\alpha$-Fe segregated at this interface between arrows. 


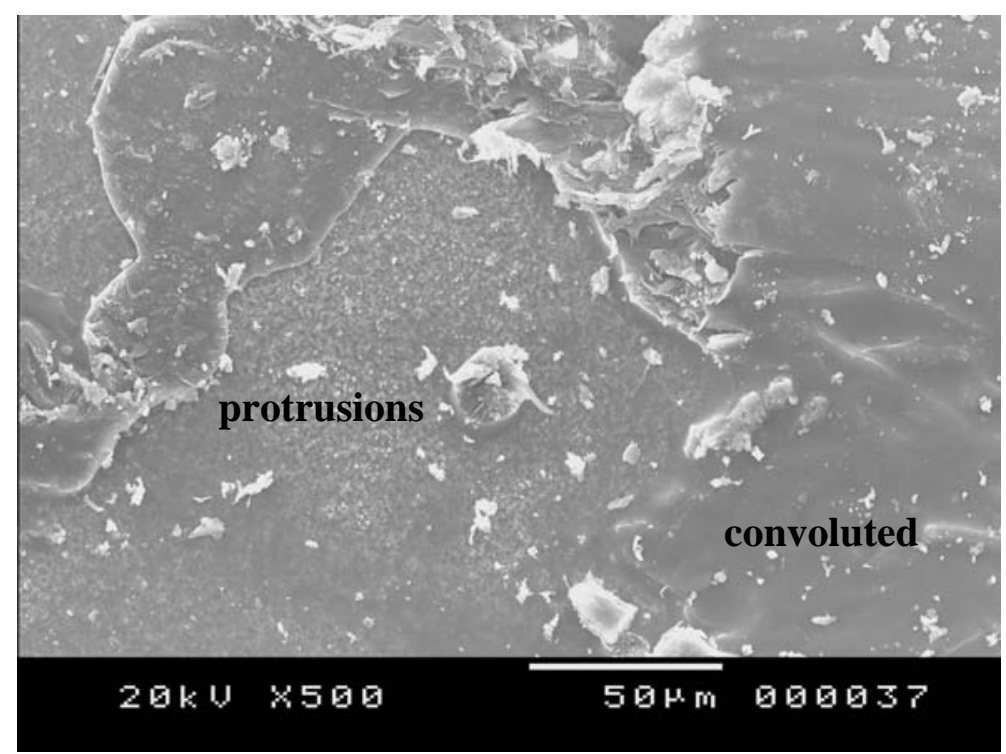

Figure 3.- SEM surface morphology after oxidation of the nitrided specimens at $800^{\circ} \mathrm{C}$ for $24 \mathrm{~h}$ showing extensive spallation. 


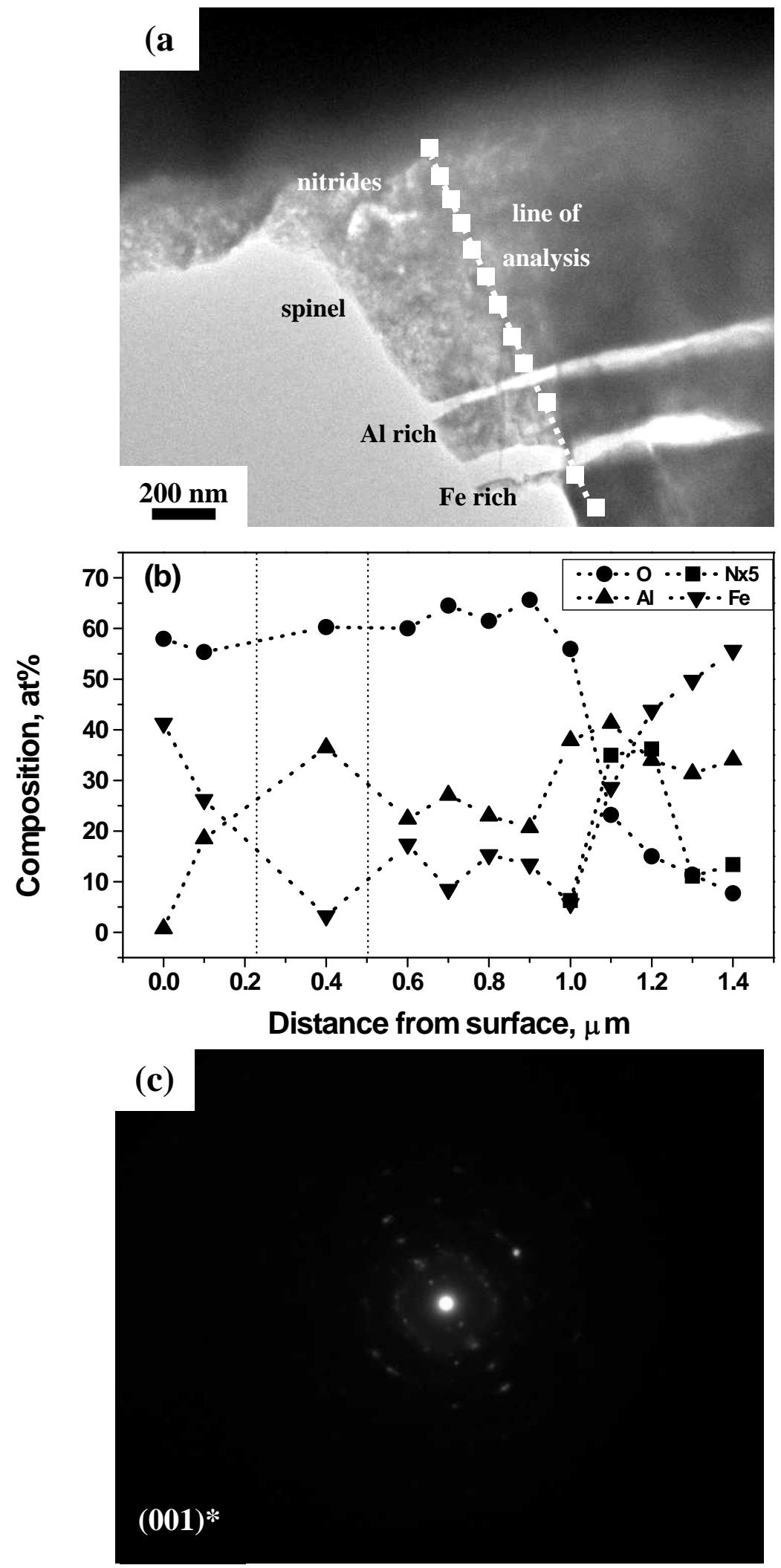

Figure 4.- (a) Bright field TEM image of the stratified oxide scale, (b) EDS microanalyses across all the layers and (c) SADP at the inner scale/substrate interface. 